\title{
Disseminated histoplasmosis: a rare cause of multiple ulcers in the gastrointestinal tract
}
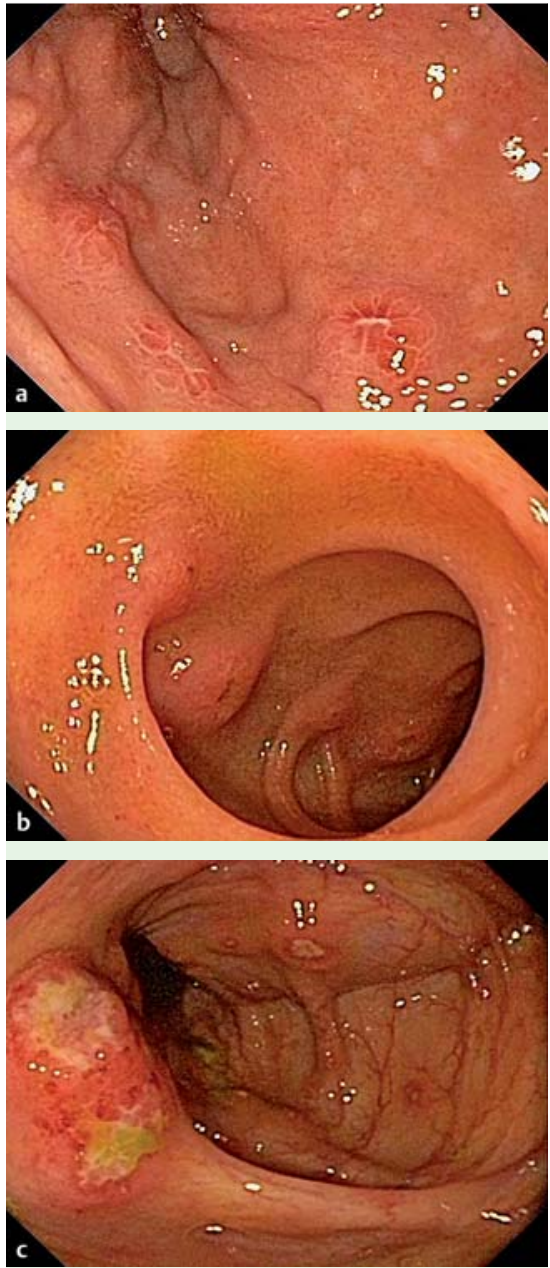

Fig. 1 Aphthoid ulcers: a gastric; $\mathbf{b}$ duodenal and $\mathbf{c}$ colonic.

Histoplasmosis is an invasive fungal infection that commonly presents as a pulmonary disease. The development of the disseminated form depends on the host's immunity and involves the gastrointestinal tract in $70 \%-90 \%$ of autopsy studies [1]. The colon may be involved in 59.6\%, followed by the small bowel [1]. Polypoid lesions, ulcerations, strictures, and perforations can be observed $[2,3]$. The concomitant involvement of the upper and lower gastrointestinal tract has never been described in vivo. Furthermore, there are few reports of histoplasmosis after liver transplantation [4]. Here we describe a case of disseminated histoplasmosis in a patient following liver transplantation manifesting as gastric, duode-

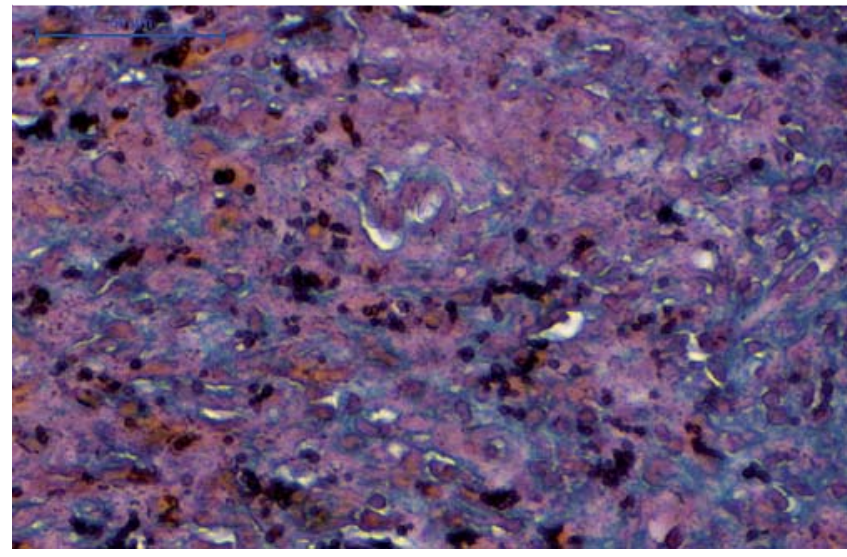

Fig. 2 At high magnification, numerous uniform oval-shaped yeasts suggestive of Histoplasma capsulatum are seen within the granulomas (Gomori methenamine silver stain $\times 40$ ).

nal, and colonic ulcers, a presentation that has not been described previously. A 68-year-old woman presented at Albert Einstein Hospital in May 2010 with abdominal pain. She had a liver transplantation 1 year ago. A computed tomography (CT) scan revealed lymph nodes in the liver hilum. During the endoscopic evaluation (endoscopy and colonoscopy), we found many small gastric, duodenal, and colonic aphthoid ulcers ( $\bullet$ Fig. 1).

Histological examination of the biopsy samples showed a chronic fungal granulomatous process consistent with histoplasmosis ( Fig. 2 ).

The patient was started on itraconazole. At 2 months, she was asymptomatic and the follow-up endoscopic and histopathological examinations were normal.

Disseminated histoplasmosis is rare and the presence of lesions in the gastrointestinal tract is even more uncommon. There are a few published articles reporting the disseminated form; most of them have been reported in patients with acquired immune deficiency syndrome and none in patients following liver transplantation. The present case is the first description of histoplasmosis manifesting as diffusely spread gastric, duodenal, and colonic ulcers. We have described this unusual presentation to alert gastroenterologists of the possibility of this disease in immunosuppressed patients.

Endoscopy_UCTN_Code_CCL_1AD_2AZ

Competing interests: None
R. Colaiacovo, A. C. F. de Castro, C. Shiang, R. L. Ganc, A. P. Ferrari Jr. Albert Einstein Jewish Hospital,

São Paulo, Brazil

\section{References}

1 Kauffman CA. Histoplasmosis: a clinical and laboratory update. Clin Microbiol Rev 2007; 20: $115-132$

2 Kahi CJ, Wheat LJ, Allen SD et al. Gastrointestinal histoplasmosis. Am J Gastroenterol 2005; 100: 220-231

3 Goodwin RA Jr., Shapiro JL, Thurman GH, Thurman SS. Disseminated histoplasmosis: clinical and pathological correlations. Medicine (Baltimore) 1980; 59: 1 - 33

4 Assi M, McKinsey DS, Driks MR et al. Gastrointestinal histoplasmosis in the acquired immunodeficiency syndrome: report of 18 cases and literature review. Diag Microbiol Infect Dis 2006; 55: 195-201

Bibliography

DOI $10.1055 / \mathrm{s}-0030-1256398$

Endoscopy 2011; 43: E216

(c) Georg Thieme Verlag KG Stuttgart · New York . ISSN 0013-726X

\section{Corresponding author}

\section{A. C. F. de Castro}

Albert Einstein Jewish Hospital

Rua Canuto du Val

88 ap 141

São Paulo-SP

Brazil 01224-040

anacfcastro@uol.com.br 